\section{Reply to 'Influenza follicles and their buds as early diagnostic markers of influenza: typical images' and demonstration of lymphoid follicles in the posterior pharyngeal walls of patients with mycoplasmal pneumonia}

Previously, the 'Images in Medicine' section of the Postgraduate Medical Journal published a letter by Miyamoto and Watanabe ${ }^{1}$ regarding an earlier article on influenza follicles that we had presented, ${ }^{2}$ informing us of an English translation of the ATLAS SAKUMA. ${ }^{3}$ We wish to express our gratitude for the images of influenza follicles presented by Miyamoto and Watanabe, ${ }^{1}$ which very clearly depict lymphoid follicles in the posterior pharyngeal wall; our images were less clear. Although the lesions we presented could have been misidentified as Yamada/Fukutomi classification type I gastric polypoid lesions, macroscopic review confirmed them to be Yamada/Fukutomi classification type II gastric polypoid lesions.

We believe that Japanese clinical physicians and patients depend on rapid influenza diagnostic kits rather than on clinical acumen (medical interviews and physical examination findings) in establishing a diagnosis of influenza. However, extensive experience is needed to ensure rigorous identification and interpretation of macroscopic findings. In this light, we appreciate the finding by Miyamoto and Watanabe that influenza follicles in the pharynx could be used as a diagnostic tool. The accuracy of the clinical criteria for diagnosing influenza ${ }^{4}$ - which comprise fever plus cough, myalgia, duration $<48$ hours, and chills or sweats-may be improved by adding the presence of influenza follicles.

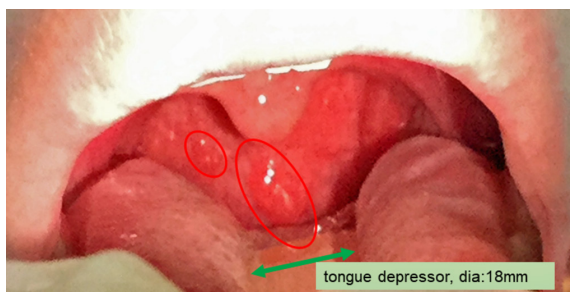

Figure 1 Pharyngeal findings from case 1. Lymphoid follicles with diameters of 7 $\mathrm{mm}$ and $13 \mathrm{~mm}$ were identified in the posterior pharyngeal wall. The tongue depressor diameter is $18 \mathrm{~mm}$ (reference).

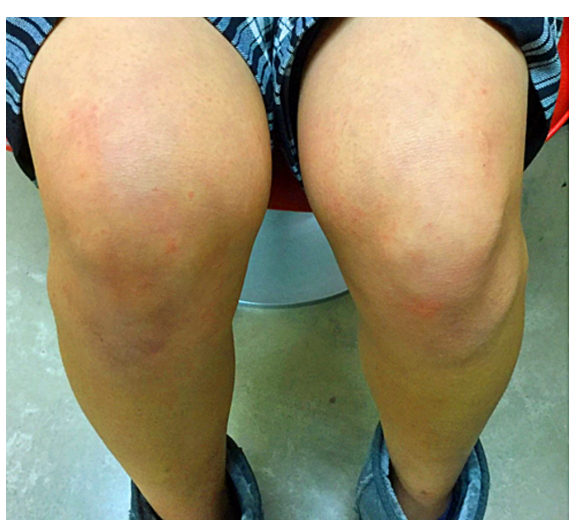

Figure 2 Lower extremity findings from case 2. Diffuse red papules were observed over both legs.

Incidentally, in our study, two patients with Mycoplasma pneumoniae infection had lymphoid follicles in the posterior pharyngeal wall; their cases are briefly presented.

\section{Case 1}

A previously healthy 21-year-old woman presented to our hospital with a 5-day history of fever $\left(38^{\circ} \mathrm{C}\right.$ at assessment), sore throat and dry cough. Lymphoid follicles with a maximum diameter of $13 \mathrm{~mm}$ were identified in the posterior pharyngeal wall (figure 1). A chest X-ray revealed infiltrative shadows in the right middle lung field. The patient was hospitalised and received empirical therapy with oral azithromycin $500 \mathrm{mg}$ daily for 3 days and intravenous ceftriaxone $2 \mathrm{~g}$ daily. Her M. pneumoniae antibody titres were 1:40 (passive agglutination) on admission and 1:1280 on day 6 of hospitalisation. Therefore, she was diagnosed with mycoplasmal pneumonia.

\section{Case 2}

A previously healthy 16-year-old woman had visited her primary care physician with a fever $\left(39^{\circ} \mathrm{C}\right)$ and cough 2 days before presenting to our hospital. She was diagnosed with pneumonia (based on chest X-ray findings) and was prescribed tosufloxacin $150 \mathrm{mg}$ thrice daily. However, her fever and cough persisted and she developed papules on both legs the next day (figure 2); this prompted her to visit our hospital. Lymphoid follicles with a maximum diameter of $9 \mathrm{~mm}$ were identified in the posterior pharyngeal wall (figure 3). A throat swab was positive for M. pneumoniae (loop-mediated isothermal amplification method), leading to a diagnosis of mycoplasmal pneumonia. The patient was prescribed oral azithromycin $500 \mathrm{mg}$ daily and oral fexofenadine $60 \mathrm{mg}$ twice daily for 3 days. One week later, her symptoms had resolved. An oral tosufloxacin challenge test, performed

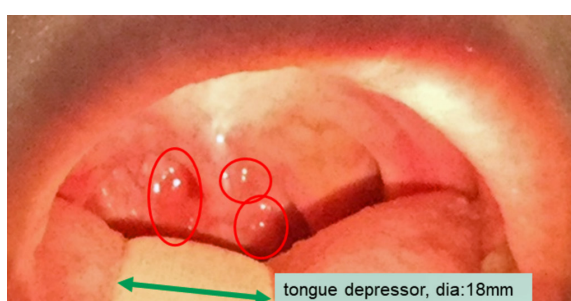

Figure 3 Pharyngeal findings from case 2. Lymphoid follicles with diameters of $5 \mathrm{~mm}, 7 \mathrm{~mm}$ and $13 \mathrm{~mm}$ were identified in the posterior pharyngeal wall. The tongue depressor diameter is $18 \mathrm{~mm}$ (reference).

2 months later, was negative. Therefore, the skin rash was determined to have been associated with M. pneumoniae infection.

Lymphoid follicles in the posterior pharyngeal wall can occur as a result of viral infections such as adenovirus and echovirus $^{3}$; these can be distinguished by shape from the characteristic influenza follicles as presented by Miyamoto and Watanabe. ${ }^{1}$ Although posterior pharyngeal wall lymphoid follicles do not normally occur with bacterial infections, we have presented two cases in which these lesions were observed in association with $M$. pneumoniae infection. These mycoplasma-associated lymphoid follicles were larger than those associated with influenza and other typical viral infections, which have a maximum diameter of approximately $10 \mathrm{~mm}$. They were few in number, were teardrop-shaped with well-defined borders and exhibited flushing. Five characteristics ${ }^{1}$ - diameter, shape, presence or absence of agglutination, and colouration-are used to assess the typical lymphoid follicles seen in cases of influenza virus infection. The lesions in our cases matched all characteristics except for their diameter. The frequency of lymphoid follicles in the posterior pharyngeal wall in such cases is unknown; further case studies must be accumulated.

Tsuneaki Kenzaka, ${ }^{1,2}$ Moe Kyotani, ${ }^{1}$ Ken Goda, Hozuka Akita ${ }^{1}$

'Department of Internal Medicine, Hyogo Prefectural Kaibara Hospital, Tanba, Japan

${ }^{2}$ Division of Community Medicine and Career Development, Kobe University Graduate School of Medicine, Kobe, Japan

Correspondence to Dr Tsuneaki Kenzaka, Division of Community Medicine and Career Development, Kobe University Graduate School of Medicine, Hyogo, 6520032, Japan; smile.kenzaka@jichi.ac.jp

Contributors TK managed the case and the redaction and correction of the manuscript. MK and KG assisted with clinical management of the case and correction of the manuscript. HA assisted with manuscript correction 
and redaction of comments for the illustrations. All authors read and approved the final manuscript.

Competing interests None declared.

Patient consent Obtained

Provenance and peer review Not commissioned; internally peer reviewed.

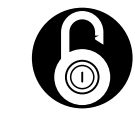

\section{OPEN ACCESS}

Open Access This is an Open Access article distributed in accordance with the Creative Commons Attribution Non Commercial (CC BY-NC 4.0) license, which permits others to distribute, remix, adapt, build upon this work non-commercially, and license their derivative works on different terms, provided the original work is properly cited and the use is non-commercial. See: http:// creativecommons.org/licenses/by-nc/4.0/

(c) Article author(s) (or their employer(s) unless otherwise stated in the text of the article) 2018. All rights reserved. No commercial use is permitted unless otherwise expressly granted.

\section{Check for updates}

To cite Kenzaka T, Kyotani M, Goda K, et al. Postgrad Med J 2018:94:311-312.

Accepted 27 January 2018

Published Online First 12 February 2018
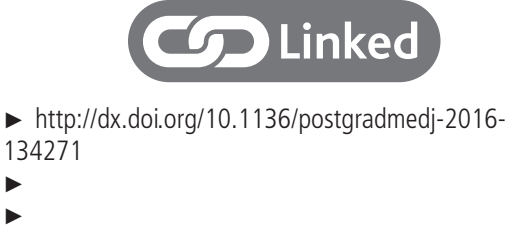

Postgrad Med J 2018;94:311-312.

doi:10.1136/postgradmedj-2017-135540

\section{REFERENCES}

1 Miyamoto A, Watanabe S. Influenza follicles and their buds as early diagnostic markers of influenza: typical images. Postgrad Med J 2016;92:560-1.

2 Kenzaka T. Influenza follicles in the posterior pharyngeal wall. Postgrad Med J 2015;91:472.

3 Sakuma T. Infant and Children's Pharynx and Skin with Infectious Disease: Virological Observations and Diagnoses with Clinical Photographs. Fukuoka, Japan: Shoshi Kankanbou, System Create Co., Ltd, 2008.

4 Ebell MH, Afonso AM, Gonzales R, et al. Development and validation of a clinical decision rule for the diagnosis of influenza. J Am Board Fam Med 2012:25:55-62.

What factors influenced the choice of medical specialty for doctors surveyed in the final year at medical school and again having entered their specialty training destination?

An overall shortfall in the number of medical graduates for current service demand and the desire for more flexibility, coupled with more rigid postgraduate medical training pathways, have emphasised the need to improve careers guidance at undergraduate and postgraduate level. Decision-making in medical careers has become of growing interest particularly with current and anticipated future shortages of doctors in some areas of medical practice.

The need to understand why and how junior doctors decide on their specialty of choice has never been more relevant in establishing if these decisions can be influenced towards areas in greatest need of increased manpower. Evidence on the factors influencing medical careers continues to evolve, but there remains limited information on whether these influences change for individual doctors over time.

A small cohort study at University of Dundee Medical school set out to explore prospectively how the influences on specialty choice change as medical trainees progress through their training journey. Questionnaires to examine career intentions and the factors influencing the choice of career were distributed to undergraduate final year students for two consecutive years between 2006 and 2008 $(n=220)$. Follow-up questionnaires were distributed to those who could be identified and located from the same two cohorts 7 and 8 years later $(n=124)$ to establish training destination and associated career influencers at that stage in their careers.

The most significant influencing factor reported by the students was exposure and positive experience as an undergraduate. For those trainees who were training in their original first or second choice of specialty, this experience was still felt to be the most important influencing factor in deciding their choice as a specialty trainee. However, for trainees who were pursuing different career paths than those preferred when they finished medical school, domestic circumstances followed by hours and conditions of work had become the pertinent influencers.

Nearly half (47.6\%) of the doctors were pursuing a career in the same specialty they had identified as their first choice when they were in final year-emphasising that positive early exposure and experience in a specialty is a long-term influencer. These findings agree with previous work highlighting the importance of previous experience in shaping career choice, ${ }^{1}$ but a number of complex and evolving factors ${ }^{2}$ such as the role of domestic circumstances have an increasing effect as careers develop and circumstances change. ${ }^{3}$
Doctors selecting general practice as a first career choice vary widely between medical schools, suggesting that medical schools that place more importance on demonstrating a positive experience of GP among their students are more likely to produce trainees choosing GP as a specialty. ${ }^{4}$ However, experience of a particular teacher or department has been found to have a significantly larger effect on doctors choosing surgery as a career compared with general practice. ${ }^{6}$ A negative attitude expressed by teachers to certain specialties also appears to discourage certain choices with reported denigration towards psychiatry and general practice adversely affecting the desire to apply to these specialties. ${ }^{7}$ The quality of experience or the enthusiasm of a particular tutor at medical school may therefore increase the attractiveness of particular specialities for future doctors.

Crisis in recruitment and retention in general practice, emergency medicine, core psychiatry and paediatrics is well recognised. In order to translate medical students into doctors in these specialties, positive teaching and clinical experiences in these areas at medical school is paramount. Some initiatives, in which the curriculum has a community focus largely taught by general practitioners, aim to encourage recruitment to general practice.

Experience in specialties as a medical student has a strong and long-lasting influence on specialty destination. The undergraduate curriculum must be continually reviewed to influence career choices to produce a workforce that meets evolving healthcare needs. Similarly, recognition that domestic circumstances become an increasingly relevant influencer in specialty choice for postgraduates and flexibility in training structures have become increasingly important.

\section{Elaine McNaughton,,}

James Riches,, Graeme Harrison,, Gary Mires,, Caroline MacEwen

NHS Education for Scotland, East Region, University of Dundee, Dundee, UK

Correspondence to Dr Elaine McNaughton, NHS Education for Scotland, East Region, University of Dundee, Dundee DD1 4HN, UK; emcnaughton@nhs.net

Contributors All listed authors fulfil the criteria for authorship and have made a substantive contribution to this study as follows: EM, CM and GM conducted the initial project plan and maintained continuous overview of the project. EM conducted the first undergraduate survey design and GM disseminated to both cohorts. GM analysed and summarised the results. GH conducted the literature review and designed the follow-up survey, secured ethical approval, identified both cohorts and distributed the survey. JR conducted the comparative analysis of all the results and produced the initial study report. CM and EM wrote the study paper 
and conducted the subsequent editing of the letter submission with joint responsibility for overall content.

Funding No external funding was required. The project was jointly supported by the University of Dundee and NHS Education for Scotland (NES).

Competing interests None declared.

Patient consent Not required.

Ethics approval The study received the approval of the University of Dundee Research Ethics committee.

Provenance and peer review Not commissioned; externally peer reviewed.

(c) Article author(s) (or their employer(s) unless otherwise stated in the text of the article) 2018. All rights reserved. No commercial use is permitted unless otherwise expressly granted.

\section{A) Check for updates}

To cite McNaughton E, Riches J, Harrison G, et al. Postgrad Med J 2018;94:311-312. Epub ahead of print: [please include Day Month Year]. doi:10.1136/ postgradmedj-2017-135370

Accepted 8 February 2018

Published Online First 23 February 2018

Postgrad Med J 2018; 2018;94:311-312.

doi:10.1136/postgradmedj-2017-135370

\section{REFERENCES}

$1 \mathrm{Ko} \mathrm{H}$, Lee T, Leung Y, et al. Factors influencing career choices made by medical students, residents, and practising physicians. BCMJ 2007;49:482-9.

2 Cleland J, Johnston P, Mattick K, et al. Understanding push-pull factors in medical careers decision making. Final report: NHS Education for Scotland, 2013. http:// www.smerc.org.uk/projects/understanding-push-pullfactors-medical-careers\%E2\%80\%99-decision-making

3 Smith F, Lambert TW, Goldacre MJ. Factors influencing junior doctors' choices of future specialty: trends over time and demographics based on results from UK national surveys. J R Soc Med 2015:108:396-405.

4 Lambert T, Goldacre M. Trends in doctors' early career choices for general practice in the UK: longitudinal questionnaire surveys. $\mathrm{Br} / \mathrm{Gen}$ Pract 2011;61:397-403.

5 Wiener-Ogilvie S, Begg D, Dixon G. Foundation doctors career choice and factors influencing career choice. Educ Prim Care 2015:26:395-403.

6 Goldacre MJ, Laxton L, Harrison EM, et al. Early career choices and successful career progression in surgery in the UK: prospective cohort studies. BMC Surg 2010;10:32.

7 Ajaz A, David R, Brown D, et al. BASH: badmouthing, attitudes and stigmatisation in healthcare as experienced by medical students. BJPsych Bull 2016:40:97-102. 